\title{
Clinicopathologic Significance of Histologic Grade, Pgp, and P53 Expression in Canine Lymphoma
}

\author{
Ravinder S. Dhaliwal, MS, DVM, DACVIM, DABVP*, Barbara E. Kitchell, PhD, DVM, DACVIM, \\ EJ Ehrhart, PhD, DVM, DACVP, Victor E. Valli, PhD, DVM, DACVP, Nikolaos G. Dervisis, PhD, DVM, DACVIM
}

\begin{abstract}
To characterize the expression of P-glycoprotein (Pgp) and p53 in different histologic grades of canine multicentric lymphosarcoma (LSA), 31 cases of LSA without prior treatment were studied. The expression levels of the Pgp and p53 proteins were evaluated for their clinicopathologic significance among standard histologic evaluation. Immunohistochemistry (IHC) was performed on formalin-fixed, paraffin-embedded archival samples of 31 previously untreated LSA cases to detect the expression of Pgp and p53. All dogs were subsequently treated with a combination chemotherapy protocol. Remission and survival durations were evaluated for correlation with histologic grade and presence of drug resistance markers. Of the 31 cases, $24(80 \%)$ and $7(22 \%)$ were positive for Pgp and p53, respectively. Overall, the median survival and duration of remission in the study was 246 days and 137 days, respectively. The National Cancer Institute working formulation histologic grade was not associated with either survival or duration of first remission (DOR). The Pgp protein expression and DOR and survival was not statistically significant. Expression of p53 was statistically correlated with survival. (J Am Anim Hosp Assoc 2013; 49:175-184. DOI 10.5326/JAAHA-MS-5843)
\end{abstract}

\section{Introduction}

Malignant lymphosarcoma (LSA) comprises approximately 7-24\% of all canine neoplasms and is the third most commonly encountered malignancy in canine patients. ${ }^{1,2}$ That type of cancer is a clonal proliferation of malignant lymphocytes in solid tissues such as lymph nodes, bone marrow, or visceral organs. LSA treatment is characterized by early spectacular response, often followed by equally spectacular treatment failure., ${ }^{3,4}$ One of the greatest clinical challenges facing LSA patients is to achieve a sustainable, long-term remission. Resistance to chemotherapeutic agents is a major impediment to the successful treatment of human and animal cancers. Drug resistance in the clinical setting encompasses all classes of chemotherapeutic agents, including alkylating agents, anthracyclines, platinum compounds, antimetabolites, natural products, and hormones. ${ }^{5-8}$ Multidrug resistance (MDR) is related to the expression of a family of adenosine triphosphate-dependent cell membrane transport pumps. The MDR1 gene encodes a transmembrane P-glycoprotein (Pgp) that functions as an energy-dependent transmembrane drug efflux pump that expels drugs from the tumor cell., ${ }^{6,9}$

In some types of tumors, drug resistance is either an inherent or intrinsic property of the malignant cell. Pgp occurs in every organism and protects the tissue from xenobiotics; thus, responsible for intrinsic resistance. Other possible causes of intrinsic resistance in cancer cells include the following: the transporter MRP1, which also acts as a drug efflux pump; resistance by
From the Center for Comparative Oncology, Michigan State University, East Lansing, MI (B.K., N.D.); Department of Microbiology, Immunology, and Pathology, College of Veterinary Medicine and Biomedical Sciences, Colorado State University, Fort Collins, CO (E.E.); and VDx Veterinary Diagnostics, Davis, CA (V.V.).

Correspondence: ravidvm@sbcglobal.net (R.D.)
CR complete remission; DOR duration of first remission; IHC immunohistochemistry; LRP lung-resistance protein; LSA lymphosarcoma; MDR multidrug resistance; OS overall survival; Pgp P-glycoprotein

${ }^{*} \mathrm{R}$. Dhaliwal's present affiliation is VCA All Care Animal Referral Center, Fountain Valley, CA. 
a mutation that results in alterations in the surface of cells leading to impaired endocytosis; and mutation in $\beta$-tubulin that can cause alterations in binding. Intrinsic resistance due to inherent tumor cell characteristics is thought to be the major cause of chemotherapy failure, especially in acute leukemia of humans. ${ }^{6-10}$ In most cases, the drug resistant phenotype is acquired through contact with sublethal drug/chemical exposures. Acquired drug resistance accounts for failure of chemotherapy after initial complete remission has been obtained for a period of time. Substrates for Pgp are hydrophobic, lipophilic, ringed xenobiotics (such as anthracyclines, vinca alkaloids, and other agents). ${ }^{10}$ Previous studies have demonstrated the presence of MDR1 gene products in drug resistant canine LSA. ${ }^{11-13}$ In 1995, Moore et al. reported Pgp positivity in 1 of the 30 pretreated canine LSA samples and in 3 of the 8 relapsed cases evaluated. ${ }^{11}$ Similarly, in the following yr, Bergman et al. evaluated the prevalence of Pgp prior to chemotherapy, at relapse, and at necropsy in 15 of 58 dogs with LSA. Those researchers concluded that the frequency of positive staining was significantly higher in postchemotherapy samples compared with the prechemotherapy samples. ${ }^{12}$ Both of those studies used a C219 monoclonal antibody; however, the former study used a semiquantitiative Western blot method and the later used immunohistochemistry (IHC). In another study, de novo Pgp expression was observed in 30 of 91 canine LSA cases (33\%) using C494 and C219 antibodies. That same study showed increased Pgp expression in relapsed dogs. ${ }^{13}$ Other molecular factors that may influence chemoresistance include p53, members of the $B C L$ gene family, MDR-associated protein, canalicular multispecific organic anion transporter, and lung-resistance protein (LRP). ${ }^{14,15}$

The p53 gene is reportedly mutated in the majority of human and canine cancers. ${ }^{16-26}$ Mutations of the p53 gene are associated with a number of canine lymphoid and nonlymphoid cancers such as osteosarcoma, LSA, and various carcinomas. ${ }^{18-26}$ The wild-type p53 protein is located in the cell nucleus and binds to specific DNA sequences. After DNA damage and other cellular insults, p53 plays an important role in DNA repair and cellular transcription. Cells that have p53 mutations are resistant to standard antineoplastic strategies that induce DNA damage, such as chemotherapy and radiotherapy. ${ }^{27}$ The wild-type $\mathrm{p} 53$ protein has a very short half-life and is normally present in a small quantity such that it cannot be detected by routine IHC methods. ${ }^{28-30}$ Other more sensitive methods of detecting p53 mutations include DNA sequencing and polymerase chain reaction-based techniques. The purposes of the current study were to evaluate the significance of Pgp and p53 as MDR markers in spontaneous canine LSA, to investigate whether a correlation between the histologic grade of canine LSA existed, and to provide IHC evidence of those proteins.

\section{Materials and Methods}

Dogs with histologically confirmed, previously untreated, multicentric LSA were eligible for evaluation in this study. Each dog was clinically evaluated prior to treatment either at the Veterinary Medical Teaching Hospital, College of Veterinary Medicine, University of Illinois, Champaign Urbana or at VCA All Care Animal Referral Center, Fountain Valley, CA. Clinical stage was determined for all dogs based on physical examination, complete hematologic and serum biochemical analyses, thoracic radiographs, and abdominal radiographs/ultrasound. All dogs were treated with a combination chemotherapy protocol consisting of L-asparaginase ${ }^{\mathrm{a}}$, vincristine ${ }^{\mathrm{b}}$, prednisone ${ }^{\mathrm{c}}$, cyclophosphamide $^{\mathrm{d}}$, and doxorubicin ${ }^{\mathrm{e}}$ (Table 1). ${ }^{31}$ Clinical responses were defined as complete remission (CR), partial remission, and progressive disease. In CR, peripheral lymphadenopathy could not be detected on physical examination. Partial remission was defined as shrinkage of peripheral lymphadenopathy by $>50 \%$ but $<100 \%$. Progressive disease was defined as enlargement of the peripheral lymph nodes by $\geq 50 \%$. Survival was defined as the time from the date of diagnosis until the date of death. Duration of first

\section{TABLE 1}

\section{Description of the Combination Chemotherapy Protocol Used in This Study}

\begin{tabular}{|c|c|c|}
\hline Drug & Dosage & Schedule \\
\hline Vincristine & $0.5-0.7 \mathrm{mg} / \mathrm{m}^{2} \mathrm{IV}$ & $\begin{array}{l}\text { Day } 1 \text { of each wk for } 8 \text { consecutive wk. After } 8 \text { wk, maintenance regimen includes day } 1 \text { every other wk for } 2 \text { wk, } \\
\text { then day } 1 \text { every third wk for } 3 \text { wk, then day } 1 \text { every } 4 \text { th wk for } 4 \text { wk, then day } 1 \text { every } 6 \text { th wk for } 1 \text { yr }\end{array}$ \\
\hline L-asparaginase & $10,000 \mathrm{IU} / \mathrm{m}^{2} \mathrm{IM}$ & Day 1 of wk 1 and 2 \\
\hline Cyclophosphamide & $50 \mathrm{mg} / \mathrm{m}^{2} \mathrm{PO}$ & Once $q 48 \mathrm{hr}$ for $8 \mathrm{wk}$ \\
\hline Doxorubicin & $30 \mathrm{mg} / \mathrm{m}^{2} \mathrm{IV}$ & Day 1 of wk 6,9 , and 12 \\
\hline Prednisone & $20 \mathrm{mg} / \mathrm{m}^{2} \mathrm{PO}$ & Daily for the first wk, then $q 48 \mathrm{hr}$ for $2-5 \mathrm{wk}$, then $10 \mathrm{mg} / \mathrm{m} 2 q 48 \mathrm{hr}$ \\
\hline Chlorambucil & $4 \mathrm{mg} / \mathrm{m}^{2} \mathrm{PO}$ & $q 48 \mathrm{hr}$ starting on wk 9 . Continue for up to $2 \mathrm{yr}$ if complete remission is maintained \\
\hline
\end{tabular}

IM, intramuscular; PO per os. 
remission (DOR) was defined as time from the date of CR until clinical relapse.

Formalin-fixed, paraffin-embedded archival tumor blocks were analyzed. The samples were obtained from the Veterinary Diagnostic Laboratory at the University of Illinois, Colorado State University, and a commercial laboratory ${ }^{f}$. Tumor blocks were sectioned ( $4 \mu \mathrm{m}$ thick) for histology and IHC. One section of each case, stained with hematoxylin and eosin, was reviewed and classified by a single pathologist (V.V.), who had no prior knowledge of the clinical stage and the treatment outcome of the patients. Cases were classified according to the National Cancer Institute working formulation into low, intermediate, and high LSA grades. ${ }^{32,33}$ Mitotic index was scored from 1 to 3 , where a score of 1 indicated $<5$ mitoses/high-power field, a score of 2 was 6-10 mitoses/ high-power field, and a score of 3 indicated $>10$ mitoses/ high-power field. ${ }^{34}$

Formalin-fixed, paraffin-embedded sections (4 $\mu \mathrm{m}$ thick) were deparaffinized in xylene and dehydrated in descending ethanol solutions to buffer. For antigen retrieval, slides were incubated in $80^{\circ} \mathrm{C}$ distilled water $(\mathrm{pH} 6)$ for $15 \mathrm{~min}$, then cooled down to room temperature over $30 \mathrm{~min}$. Slides were washed in Tris buffer ( $\mathrm{pH}$ 7.6). Endogenous peroxidase was quenched by immersion in $3 \%$ hydrogen peroxide with methanol $(10 \mathrm{~mL}$ of $30 \%$ hydrogen peroxide in $90 \mathrm{~mL}$ of methanol) for two separate 5 min intervals, and then washed with Tris buffer ( $\mathrm{pH}$ 7.6) three times over $5 \mathrm{~min}$. Shandon's Sequenza ${ }^{\mathrm{g}}$ apparatus in a humidity chamber was used for slide preparation. A protein block was performed with $10 \%$ normal goat serum at room temperature for $20 \mathrm{~min}$ to suppress nonspecific binding of immunoglobulin. Subsequently, slides were incubated overnight at room temperature in a humidity chamber with the primary antibodies (antiPgp monoclonal antibody ${ }^{\text {h }}$ [C494] at $3 \mathrm{mg} / \mathrm{mL}$ and rabbit antihuman p53 polyclonal antibody $\mathrm{CM}^{\mathrm{i}}$ at prediluted concentration). ${ }^{13,17-19}$ For negative controls, nonimmune serum was substituted for the primary antibody. The sections were washed with Tris buffer before an indirect biotin-streptavidin amplified (B-SA) detection system was applied ${ }^{j}$ with diaminobenzidine tetrahydrochloride substrate. The sections were then counterstained with hematoxylin, dehydrated with ascending ethanol solutions, bathed in xylene and clearite, and coverslipped with permanent mounting medium. Immunophenotyping was also performed with $C D 79 \mathrm{a}^{\mathrm{k}}$ as a $\mathrm{B}$-cell marker and $\mathrm{CD}^{1}$ as a T-cell marker on formalin-fixed, paraffin-embedded blocks.

All slides were reviewed independently by three of the authors (R.D., B.K., E.E.), who were blinded to the clinical outcome or the histologic grade of the tumor. Canine kidney was used as the positive control for Pgp analysis. Pgp staining localized to the cytoplasm and brush border of proximal tubules of the kidney as previously reported by Guo et al. (2002). ${ }^{15}$ Pgp scoring was defined as follows: negative (Pgp - ) when $\leq 50 \%$ of neoplastic cells in the field had cytoplasmic Pgp staining (Figure 1); positive $(\mathrm{Pgp}+)>50 \%$ of neoplastic cells were positive (Figure 2) ${ }^{29}$ A total of 600 cells were counted in three different high-power fields (original magnification $\times 100$ ). The fields were selected using a random table, and the peripheral areas of the section were not included to avoid misinterpretation of staining artifact. A positive canine anal sac adenocarcinoma sample (provided by courtesy of Dr. Rance Gamblin, The Ohio State University, February 16, 1997) was used as a control for p53 analysis. The p53 staining was localized to the nucleus. Results for p53 staining were defined as follows: low (p53-) when $<10 \%$ of the neoplastic cells had nuclear staining (Figure 3); and positive $(\mathrm{p} 53+)$ when $\geq 10 \%$ of neoplastic cells stained (Figure 4). For p53 analysis, regions of the highest protein expression evident at low-power scanning were analyzed. ${ }^{30}$ Quantitation of the number of positive tumor cells was performed as described for Pgp.

\section{Statistical Analysis}

Standard statistical methods were applied to evaluate the $95 \%$ confidence intervals for DOR and overall survival (OS). Logistic regression analysis (log-rank and Wilcoxon signed rank tests) with both univariate and multivariate analysis were performed to determine the impact of study variables (i.e., histologic grade, Pgp and p53 immunostaining) on OS and DOR. OS and DOR distributions were generated by the Kaplan-Meier product-limit method. Survival curves were compared using the log-rank method to test for differences in the distribution of DOR and

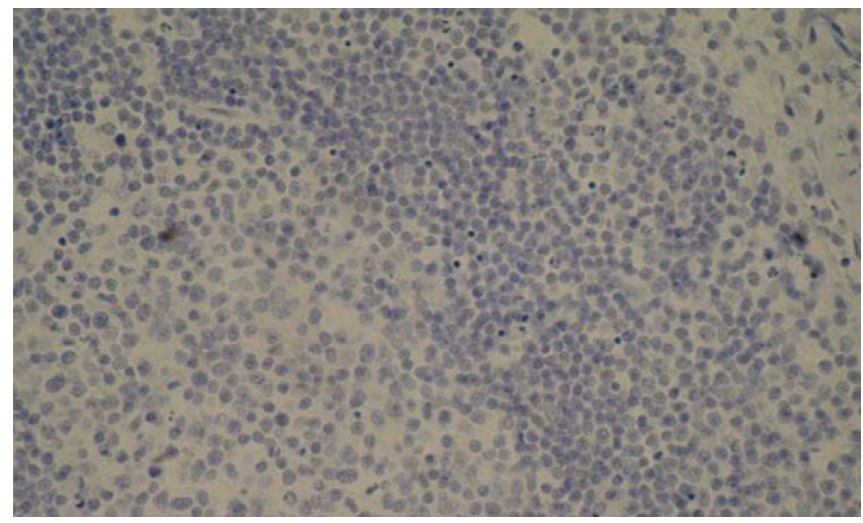

FIGURE 1 Canine lymph node with negative P-glycoprotein (Pgp) staining. The cytoplasm is unmarked, and the cells are delineated by the hematoxylin counter stain for nuclei. Original magnification $\times 100$. 


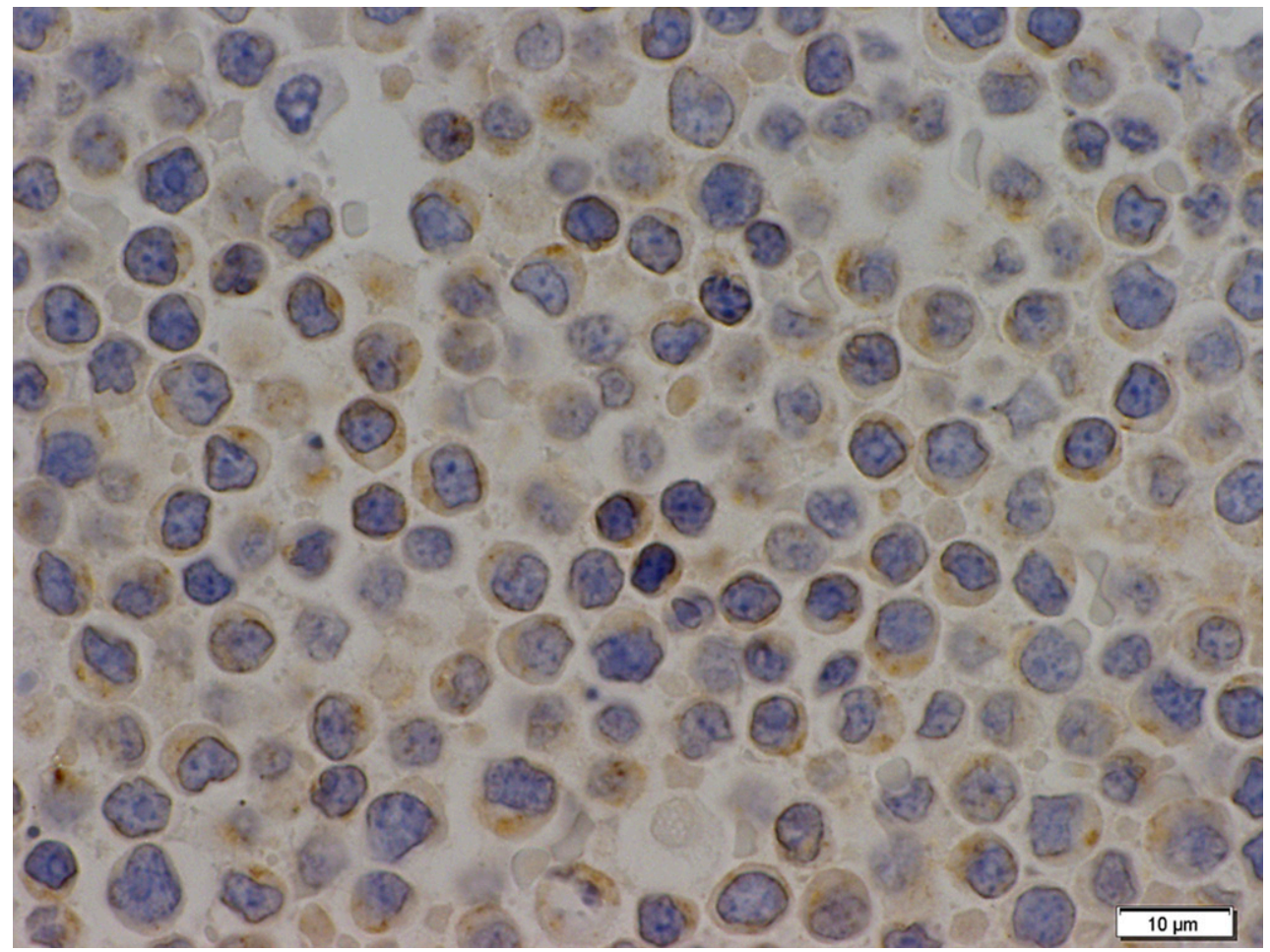

FIGURE 2 Canine lymph node with positive staining for Pgp. Note the prominent cytoplasmic staining regularly in the areas of increased cell density represented by the infiltrating neoplastic cells. Original magnification $\times 100$.

OS. Three of the 31 cases $(10 \%)$ were lost to follow-up. Those cases, along with the cases that were still alive at the time of data analysis, were censored. Statistical analyses were performed using a commercial software program ${ }^{\mathrm{m}}$. For all tests, $P<0.05$ was considered significant. The relationship of the IHC scoring for Pgp and $\mathrm{p} 53$ protein expression was correlated with OS and DOR.

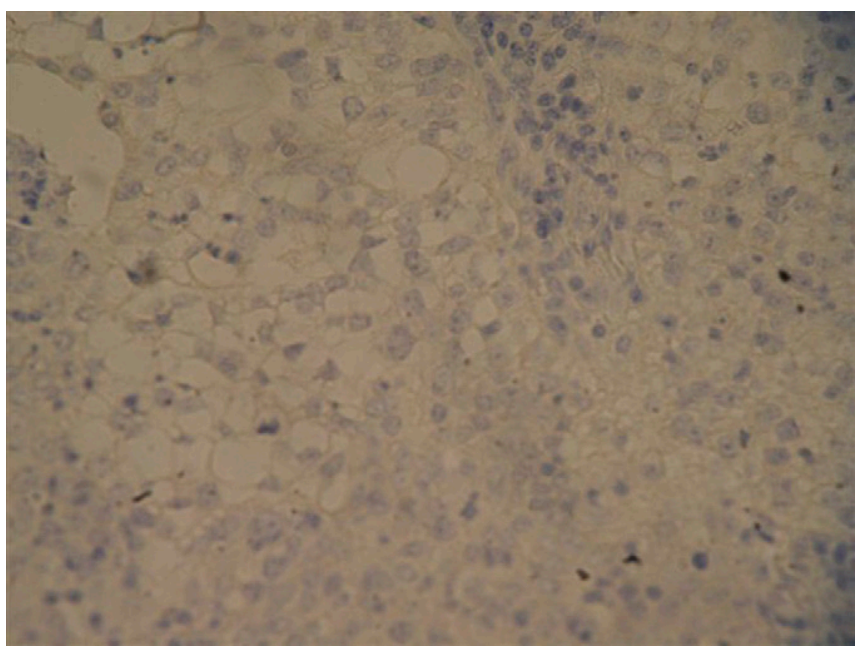

FIGURE 3 Canine lymph node with negative p53 staining. No nuclear marking for the p53 gene product is in the nuclei. Original magnification $\times 40$.

\section{Results}

Of the 37 initial blocks, six cases were excluded from the study because of insufficient sample size to accommodate all histologic and IHC assays. The clinicopathologic data of the 31 cases evaluated in this study have been summarized in Table 1.

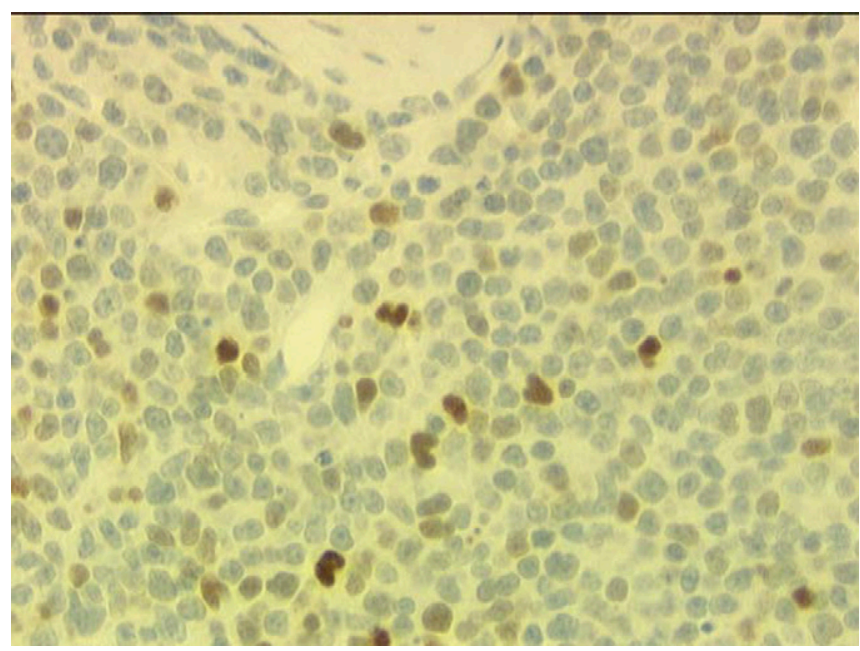

FIGURE 4 Canine lymph node with positive staining for $p 53$. At least $10 \%$ of the nuclei have some degree of nuclear marking. Original magnification $\times 40$. 
All of the dogs had peripheral lymphadenopathy at the time of initial presentation, and were determined to be either stage IIIa or IVa. Thirty-six percent $(\mathrm{n}=11)$ were high-grade, $61 \%(\mathrm{n}=19)$ were intermediate-grade, and 3\% $(n=1)$ were low-grade LSA. Low-grade lymphoma (1 of 31 cases) was uncommon in this cohort, as previously reported. ${ }^{32,33}$ Twenty-one (68\%) of the 31 dogs evaluated achieved CR during induction. Partial remission was observed in 4 of 31 dogs (13\%). Overall response rate in this study was $80 \%$. Six of the LSA cases (19\%) were Pgp -, while $25(80 \%)$ were Pgp + . Twenty-four $(77 \%)$ of the 31 LSA cases were negative, and 7 (22\%) were positive for p53 immunostaining (Table 2). The immunophenotyping information for CD79a (as a B-cell marker) and CD3 (as a T-cell marker) was available in 16 of the 31 cases. Eleven of those 16 cases were positive for
CD79a and 4 of the 16 expressed CD3. One case was positive for both, and hence, classified as T-cell rich B-cell LSA.

One dog was alive at the time of analysis, and two dogs were lost to complete follow up. One dog was lost to follow-up evaluation after relapse, thus DOR was determined, but survival information was lost. OS (from the day of histologic diagnosis) ranged from 0 days to 899 days for the 27 dogs for which the date of death was known. One dog was lost to follow-up evaluation after relapse; therefore, DOR was evaluated in this case. Mean and median OS in this study were 321 days and 246 days, respectively. The overall mean and median DOR was 180 days and 137 days, respectively. Median OS for CD79a + and CD3 + cases were 279 days and 17 days, respectively. Median OS for Pgp + and Pgp cases was 246 days and 418 days, respectively $(P \leq 0.762)$ as

TABLE 2

Summary of Clinicopathologic and Immunopositivity in 31 Dogs with Canine LSA

\begin{tabular}{|c|c|c|c|c|c|c|c|c|c|}
\hline Case & Age (yr) & Sex & Breed & Grade & Type & Pgp + & Pgp- & p53 + & p53- \\
\hline 1 & 11 & $\mathrm{CM}$ & Miniature schnauzer & High & Immunoblastic & $X$ & & & $X$ \\
\hline 2 & 8 & $\mathrm{~F}$ & Rottweiler & High & Immunoblastic & $x$ & & & $X$ \\
\hline 3 & 4.5 & SF & Basset hound & High & Immunoblastic & $X$ & & & $X$ \\
\hline 4 & 6.5 & SF & Welsh corgi & High & Immunoblastic polymorphous & $x$ & & $X$ & \\
\hline 5 & 6 & $\mathrm{CM}$ & Mixed-breed & High & Immunoblastic polymorphous & $x$ & & & $X$ \\
\hline 6 & 7 & $\mathrm{M}$ & Mixed-breed & High & Immunoblastic & $X$ & & & $X$ \\
\hline 7 & 5 & $\mathrm{CM}$ & Mixed-breed & High & Immunoblastic polymorphous & $x$ & & & $x$ \\
\hline 8 & 8 & $\mathrm{CM}$ & Australian shepherd & High & Immunoblastic polymorphous & & $X$ & & $x$ \\
\hline 9 & 6 & $\mathrm{M}$ & Golden retriever & High & Immunoblastic & & $X$ & & $X$ \\
\hline 10 & 11 & M & Mixed-breed & High & Immunoblastic & $X$ & & & $x$ \\
\hline 11 & 1 & $\mathrm{CM}$ & Mixed-breed & High & Lymphoblastic convoluted & & $X$ & & $x$ \\
\hline 12 & 5 & $\mathrm{~F}$ & Cocker spaniel & Intermediate & Diffuse large cell & $X$ & & & $X$ \\
\hline 13 & 6 & $M$ & Doberman pinscher & Intermediate & Diffuse large cell & $x$ & & $X$ & \\
\hline 14 & 4.5 & SF & Boxer & Intermediate & Diffuse large cleaved cell & $x$ & & & $X$ \\
\hline 15 & 12 & $\mathrm{~F}$ & Doberman pinscher & Intermediate & Diffuse large cell & & $X$ & $X$ & \\
\hline 16 & 9 & $\mathrm{CM}$ & Golden retriever & Intermediate & Diffuse mixed & $x$ & & & $X$ \\
\hline 17 & 6 & $\mathrm{M}$ & Rottweiler & Intermediate & Diffuse large cell & $x$ & & & $x$ \\
\hline 18 & 7 & $\mathrm{CM}$ & Mixed-breed & Intermediate & Diffuse large cell & $x$ & & & $X$ \\
\hline 19 & 1.5 & $\mathrm{M}$ & Cocker spaniel & Intermediate & Diffuse large cell & $x$ & & & $X$ \\
\hline 20 & 4 & M & Old English sheepdog & Intermediate & Diffuse large cell & $x$ & & & $X$ \\
\hline 21 & 7 & M & Cocker spaniel & Intermediate & Diffuse large cleaved cell & $x$ & & $X$ & \\
\hline 22 & 5 & $\mathrm{~F}$ & Golden retriever & Intermediate & Diffuse large cell & $x$ & & & $X$ \\
\hline 23 & 5 & $\mathrm{~F}$ & Miniature schnauzer & Intermediate & Diffuse large cleaved cell & $x$ & & & $x$ \\
\hline 24 & 6 & M & Mixed-breed & Intermediate & Follicular large cell & $X$ & & & $X$ \\
\hline 25 & 4.5 & M & Mixed-breed & Intermediate & Diffuse large cell & $x$ & & $X$ & \\
\hline 26 & 10 & $M$ & Australian shepherd & Intermediate & Follicular large cell & & $X$ & $x$ & \\
\hline 27 & 6 & SF & Doberman pinscher & Intermediate & Diffuse large cell & $X$ & & & $X$ \\
\hline 28 & 3.5 & $\mathrm{~F}$ & Cocker spaniel & Intermediate & Diffuse large cleaved cell & $x$ & & & $X$ \\
\hline 29 & 10 & SF & Alaskan malamute & Intermediate & Diffuse large cell & $x$ & & $X$ & \\
\hline 30 & 9 & $\mathrm{~F}$ & Miniature schnauzer & Intermediate & Diffuse large cell & $X$ & $x$ & & $X$ \\
\hline 31 & 10 & $\mathrm{~F}$ & Golden retriever & Low & Mantle cell & $x$ & & & $x$ \\
\hline
\end{tabular}

CM, castrated male; F, female; L, lymphoma; M, male; SF, spayed female. 
shown in Figure 5. Median OS for p53 + and p53 - cases was 151 days and 307 days, respectively $(P$ value $\leq 0.0317)$ as shown in Figure 6. Median OS and DOR for dogs with intermediategrade LSA were 217 days and 128 days, respectively, while for high-grade cases, median OS and DOR were 307 days and 192 days, respectively. Histologic grade was not statistically significant for DOR $(P \leq 0.2539)$ and survival $(P \leq 0.4987)$. Interestingly, the authors noted that the dogs with intermediate-grade LSA ( $\mathrm{n}=$ 19) had shorter median OS (217 days) compared with high-grade ( $\mathrm{n}=11)$ cases (307 days). This observation could be due to an overall small number of subjects in this study. The relationship of IHC scoring for Pgp and p53 protein expression was evaluated with OS, DOR, response, histologic grade and clinical stage (Tables 3A, B). Pgp expression influenced neither the chance to achieve a CR nor OS. The p53 expression was negative prognostically for OS $(P \leq 0.0317)$, but not for overall DOR $(P \leq 0.2573)$.

\section{Discussion}

Traditional prognostic factors for canine LSA are gender, age, body weight, clinical stage and substage, hypercalcemia, prior steroid treatment, immunophenotype, argyrophilic nucleolar organiser regions count, and histologic classification. ${ }^{33-35}$ In the current study, the authors' investigated the clinicopathologic significance of drug resistance markers, Pgp, and p53 in spontaneous canine LSA using IHC to detect the proteins in archival tissues. An additional goal was to evaluate for any correlation between those markers and histologic grade of LSA. The data failed to show any association between the histologic grade and expression of Pgp and $\mathrm{p} 53$. The results also revealed no association between the histologic grade and either DOR or OS. That was likely due to poor statistical power due to smaller sample size, which was then further compounded by subsets within an already too small population available for testing.

In veterinary medicine, Pgp expression has been investigated by IHC and Western blotting methods. ${ }^{11-13}$ In one report, 33\% of untreated canine LSA cases expressed Pgp. Moore et al. (1995) examined the expression of Pgp by Western blotting in 30 dogs with LSA prior to chemotherapy and in 9 dogs after chemotherapy. ${ }^{13}$ That study identified expression in 1 of 30 cases $(3 \%)$ before treatment and in 3 of 8 cases (38\%) posttreatment. Those results support increased Pgp expression after chemotherapy exposure. Similarly, another study reported an increased frequency of Pgp expression in canine LSA samples obtained at the time of relapse $(n=22)$ and necropsy $(n=34)$ after initiation of chemotherapy, compared with pretreatment samples. ${ }^{12}$ Those results

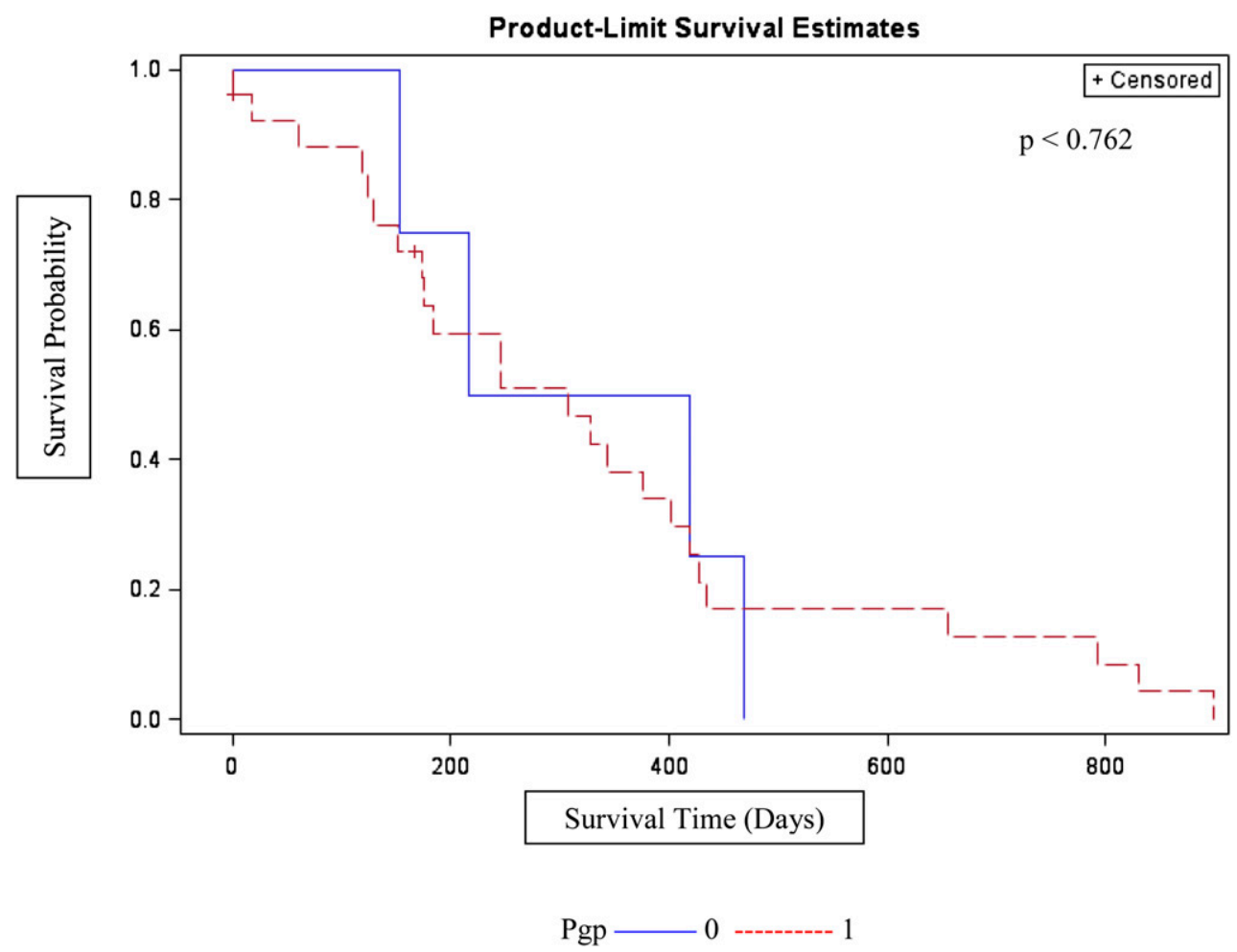

FIGURE 5 Kaplan-Meier plot depicting overall survival (OS) for dogs with Pgp immunostaining. The dotted red line represents the Pgp positive cases, and the solid blue line represents the Pgp negative cases. The crosses represent the censored data. 


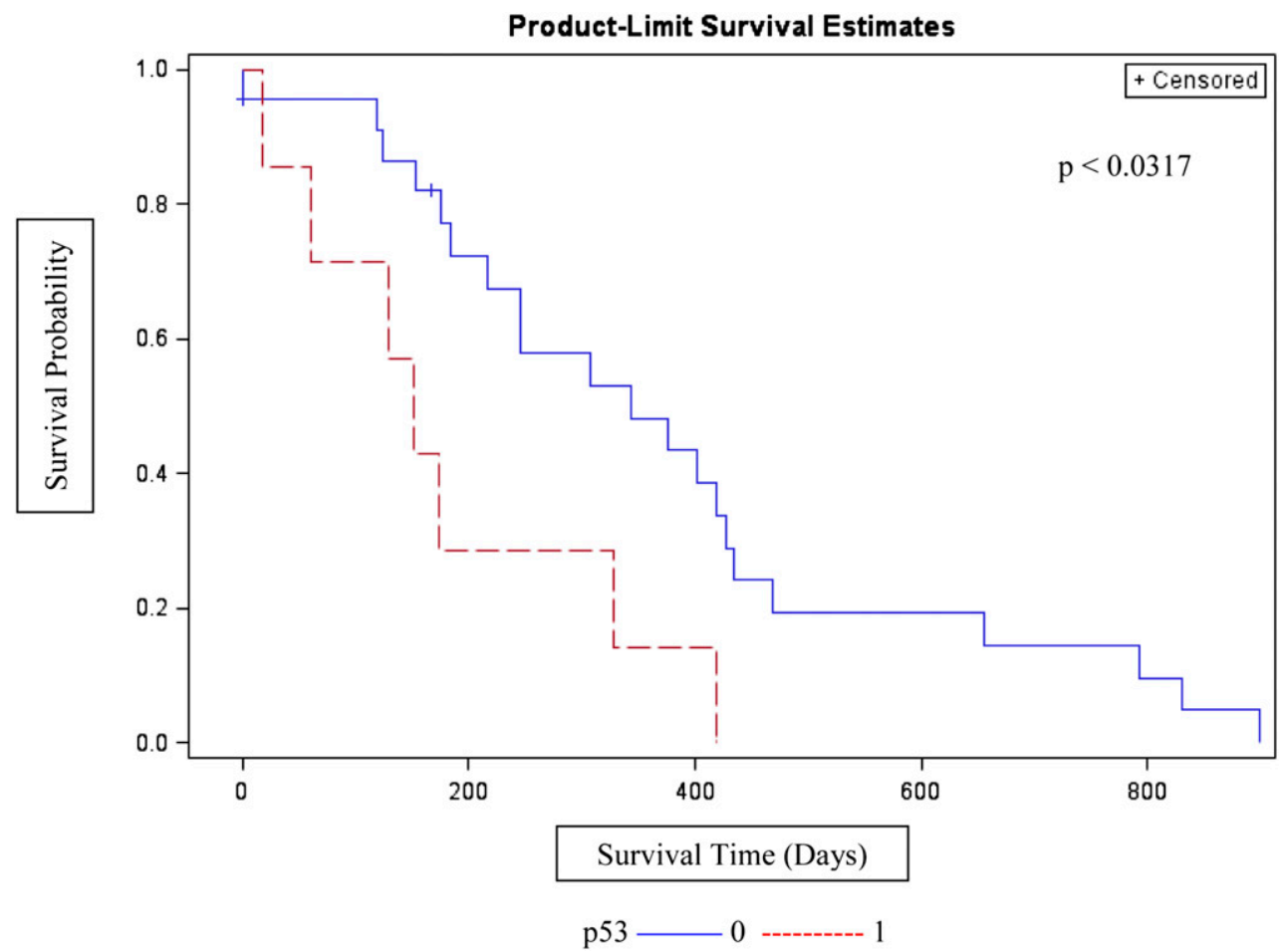

FIGURE 6 Kaplan-Meier plot showing survival in dogs with p53 expression. The p53 positivity was statistically significant (P $\leq 0.0317)$ for OS in this group. The dotted red line represents the p53 positive cases, and the solid blue line represents the p53 negative cases. The crosses represent the censored data.

are contrary to the results obtained in the current study, in which $83 \%$ of pretreatment cases had de novo Pgp expression. Possible explanations for this discrepancy include: variation in sensitivity due to difference in methodology due to different primary antibody (C219 monoclonal antibody) used; and the fact that IHC scoring was performed by an image analysis system in the published study, while in the current study, the authors' scored each section manually. ${ }^{12}$ The Western blotting technique has also been performed to detect Pgp expression in canine LSA. ${ }^{11}$ That

TABLE 3A

Results of Correlations Between IHC Markers and Survival in Dogs with Multicentric LSA

\begin{tabular}{lcccc} 
Variable & $\chi^{2}$ & $\boldsymbol{P}$ & Hazard ratio* $^{*}$ & $\mathbf{9 5 \%} \mathbf{~ C l}$ \\
\hline Survival & & & & \\
Pgp & 0.2014 & 0.762 & 0.77742 & $0.2532-2.3672$ \\
p53 & 4.6134 & 0.0317 & 0.2754 & $0.08491-0.8933$ \\
D0R & & & & \\
Pgp & 0.3109 & 0.5771 & 0.7310 & $0.2429-2.1996$ \\
p53 & 1.2834 & 0.2573 & 0.5475 & $0.1931-1.5525$
\end{tabular}

* - value $\langle 1\rangle+$ value

$\mathrm{Cl}$, confidence interval; DOR, duration of first remission; IHC, immunohistochemistry; LSA, lymphosarcoma; Pgp, P-glycoprotein. was a semiquantitative technique and might have failed to detect low levels of Pgp. Alternately, there might have been a small number of cells with high levels of expression that still could fall below the level of detectability by Western blot. The other possible explanation for the discrepancy between the current study and the previously published report was the potential for high cellular production of related drug resistance pumps, such as

TABLE 3B

Results of Correlations Between IHC Markers and Clinicopathologic Parameters

\begin{tabular}{lccc} 
Variable & $\chi^{2}$ & $\boldsymbol{P}$ & $\begin{array}{c}\text { Fisher exact test } \\
\text { (two-sided } \boldsymbol{P} \text { ) }\end{array}$ \\
\hline $\begin{array}{l}\text { Response } \\
\text { Pgp }\end{array}$ & 0.1635 & 0.6859 & 1.0000 \\
p53 & 0.4648 & 0.4954 & 0.6518 \\
Histologic grade & & & \\
$\quad$ Pgp & 0.2282 & 0.8922 & 1 \\
p53 & 2.3167 & 0.3140 & 0.3920 \\
Clinical stage & & & \\
$\quad$ Pgp & 0.4707 & 0.7903 & 1 \\
p53 & 3.1788 & 0.2040 & 0.1718 \\
\hline
\end{tabular}

IHC, immunohistochemistry; Pgp, P-glycoprotein. 
MDR-associated protein or LRP families..$^{8,19,36-42}$ One could also speculate that the authors' methodology might have crossreacted to a different isoforms of either MRP or LRP; however, in one human study, MRP expression had no impact on either OS or clinical outcome in patients with myeloid leukemia. ${ }^{40,43}$

The authors' results concur with Lee et al. (1996) and support de novo Pgp expression. Increased Pgp expression after LSA relapse has been reported by several investigators; however, Pgp expression in relapsed samples was not evaluated in this study. Strong Pgp immunoreactivity is reported to be a negative prognostic factor for survival. ${ }^{11-13}$ Similar to the authors' findings, Brenn et al. (2008), while evaluating Pgp expression in feline LSA, determined that Pgp expression was not predictive of remission or survival times in cats. ${ }^{5}$

A gold-standard method for identifying Pgp is not yet available; however, the use of a real-time polymerase chain reaction assay appears to be a more sensitive methodology than either IHC or Western analysis. This investigation represents the second study to apply antiPgp monoclonal antibody (C494) in canine LSA. Three previous studies have used C219 antibody against Pgp. ${ }^{1-13}$ The potential limitations associated with IHC are the subjective nature of the evaluation, primary antibody cross-reactivity, and a relative insensitivity based on the detection threshold of the antibody. It appears that there may be other molecular reasons for therapy failure in dogs with LSA besides Pgp overexpression. The findings reported herein are more in concert with previous human LSA studies, where $40-64 \%$ of human patients had LSA cells that expressed Pgp before chemotherapy was administered. ${ }^{37,38}$

One study has reported p53 immunostaining in $40 \%$ of canine LSA cases evaluated by IHC techniques. ${ }^{18}$ The authors of this study presume those were untreated cases, although this was not specifically stated in that manuscript. There is a discordance between the results of human studies examining the p53 gene mutation assessed either by direct mutational analysis or other molecular methods versus measuring the expression of p53 by IHC. ${ }^{21,27,28,44-51}$ Possible explanations for this variability are that the two assays are not measuring the same thing and variable p53 staining can be seen with different antibodies. IHC detection of p53 in human nonHodgkin's LSA patients revealed staining in $30-40 \%$ of cases. ${ }^{47,48}$ The results presented herein indicate $22 \%$ staining for p53 in spontaneous canine LSA. Based on this study (and from previous reports), it appears that polyclonal antibody (CM-1) has higher affinity for canine p53. ${ }^{16-19}$ The other explanation for this could be due to the local differences in the nature and organization of amino acid residues on the surface of the canine p53 molecule compared with human p53 proteins, resulting in a lack of species cross-reactivity. No canine-derived p53 monoclonal antibody is available, to the best of the authors' knowledge. The association between p53 protein expression and tumor histologic grade has been evaluated in many human tumor types. ${ }^{49-51}$ Those studies also correlated p53 protein expression with biologic behavior of tumors, such as metastasis, angiogenesis, and increased proliferation rate. In the current study, very few cases were p53 positive. The conclusion that p53 expression is rare in canine LSA parallels other studies. ${ }^{24}$ Statistically significant conclusions cannot be drawn between histologic grade and p53 expression in this series of cases; however, p53 expression was predictive for survival. In the authors' opinion, the only obvious reason for p53 expression not to be significant for DOR is the lack of statistical power and an uncommon de novo expression of p53 in canine LSA. The other explanation could be that p53 positive cases might have poor OS due to failure of the rescue protocol more than to DOR compared with p53 negative cases. In other words, survival is reduced due to failure of second remission.

\section{Conclusion}

From this study, with a small number of cases, the authors achieved the following general conclusions: that Pgp expression is common in de novo canine lymphoma, and p53 expression is uncommon in canine lymphoma.

\section{FOOTNOTES}

a L-asparaginase; Lundbeck Inc., Deerfield, IL

b Vincristine sulfate; Hospira Inc., Lake Forest, IL

c Prednisone; West-Ward Pharmaceutical Corp., Eatontown, NJ

d Cyclophosphamide; Baxter Healthcare Corp., Deerfield, IL

e Doxorubicin; Teva Parenteral Medicines Inc., Irvine, CA

f Antech Diagnostics Inc., Irvine, CA

g Shandon's Sequenza; Rankin Biomedical Corporation, Holly, MI

h Anti-P-Glycoprotein Mouse (C494) Antibody; Covance, Inc., Dedham, MA

p53 CM1 Polyclonal Antibody; Covance, Inc., Dedham, MA

j Avidin/Biotin blocking kit; Biogenex Laboratories, San Ramon, CA

k Mouse monoclonal CD79 $\alpha$; Santa Cruz Biotechnology Inc., Santa Cruz, CA

1 Polyclonal rabbit antihuman CD3; Sigma-Aldrich, St. Louis, MO

m SAS 9.3; SAS Institute, Cary, NC

\section{REFERENCES}

1. Moulton JE, Harvey JW. Tumors of lymphoid and hematopoietic tissue. In: Moulton JE, ed. Tumors of domestic animals. 3rd ed. Berkeley (CA): University of California Press; 1990:231-307.

2. Dorn CR, Taylor DON, Frye FL, et al. Survey of animal neoplasms in Alameda and Contra Costa Counties, California. I. Methodology and description of cases. J Natl Cancer Inst 1968;40(2):295-305. 
3. Northrup NC, Gieger TL, Kosarek CE, et al. Mechlorethamine, procarbazine and prednisone for the treatment of resistant lymphoma in dogs. Vet Comp Oncol 2009;7(1):38-44.

4. Bannink EO, Sauerbrey ML, Mullins MN, et al. Actinomycin D as rescue therapy in dogs with relapsed or resistant lymphoma: 49 cases (1999-2006). J Am Vet Med Assoc 2008;233(3):446-51.

5. Brenn SH, Couto SS, Craft DM, et al. Evaluation of P-glycoprotein expression in feline lymphoma and correlation with clinical outcome. Vet Comp Oncol 2008;6(3):201-11.

6. Uozurmi K, Nakaichi M, Yamamoto Y, et al. Development of multidrug resistance in a canine lymphoma cell line. Res Vet Sci 2005;78(3):217-24.

7. Fojo AT, Menefee M. Microtubule targeting agents: basic mechanisms of multidrug resistance (MDR). Semin Oncol 2005;32(6)(suppl 7): S3-8.

8. Murren JR. Modulating multidrug resistance: can we target this therapy? [editorial]. Clin Cancer Res 2002;8(3):633-5.

9. Endicott JA, Ling V. The biochemistry of P-glycoprotein-mediated multidrug resistance. Annu Rev Biochem 1989;58:137-71.

10. Marie JP. P-glycoprotein in adult hematologic malignancies. Hematol Oncol Clin North Am 1995;9(2):239-49.

11. Moore AS, Leveille CR, Reimann KA, et al. The expression of P-glycoprotein in canine lymphoma and its association with multidrug resistance. Cancer Invest 1995;13(5):475-9.

12. Bergman PJ, Ogilvie GK, Powers BE. Monoclonal antibody C219 immunohistochemistry against P-glycoprotein: sequential analysis and predictive ability in dogs with lymphoma. J Vet Intern Med 1996;10(6):354-9.

13. Lee JJ, Hughes CS, Fine RL, et al. P-glycoprotein expression in canine lymphoma: a relevant, intermediate model of multidrug resistance. Cancer 1996;77(9):1892-8.

14. Miyoshi N, Tojo E, Oishi A, et al. Immunohistochemical detection of P-glycoprotein (PGP) and multidrug resistance-associated protein (MRP) in canine cutaneous mast cell tumors. J Vet Med Sci 2002;64(6):531-3.

15. Guo A, Marinaro W, Hu P, et al. Delineating the contribution of secretory transporters in the efflux of etoposide using Madin-Darby canine kidney (MDCK) cells overexpressing P-glycoprotein (Pgp), multidrug resistance-associated protein (MRP1), and canalicular multispecific organic anion transporter (cMOAT). Drug Metab Dispos 2002;30(4):457-63.

16. Sueiro FA, Alessi AC, Vassallo J. Canine lymphomas: a morphological and immunohistochemical study of 55 cases, with observations on p53 immunoexpression. J Comp Pathol 2004;131(2-3): 207-13.

17. Veldhoen N, Stewart J, Brown R, et al. Mutations of the p53 gene in canine lymphoma and evidence for germ line p53 mutations in the dog. Oncogene 1998;16(2):249-55.

18. Gamblin RM, Sagartz JE, Couto CG. Overexpression of p53 tumor suppressor protein in spontaneously arising neoplasms of dogs. Am J Vet Res 1997;58(8):857-63.

19. Ginn PE. Immunohistochemical detection of P-glycoprotein in formalin-fixed and paraffin-embedded normal and neoplastic canine tissues. Vet Pathol 1996;33(5):533-41.

20. Levine AJ, Momand J, Finlay CA. The p53 tumour suppressor gene. Nature 1991;351(6326):453-6.

21. Vogelstein B, Kinzler KW. p53 function and dysfunction. Cell 1992; 70(4):523-6.
22. Sagartz JE, Bodley WL, Gamblin RM, et al. p53 tumor suppressor protein overexpression in osteogenic tumors of dogs. Vet Pathol 1996;33(2):213-21.

23. Sokołowska J, Cywińska A, Malicka E. p53 expression in canine lymphoma. J Vet Med A Physiol Pathol Clin Med 2005;52(4):172-5.

24. Setoguchi A, Sakai T, Okuda M, et al. Aberrations of the p53 tumor suppressor gene in various tumors in dogs. Am J Vet Res 2001;62(3): 433-9.

25. Lee $\mathrm{CH}$, Kim WH, Lim JH, et al. Mutation and overexpression of p53 as a prognostic factor in canine mammary tumors. J Vet Sci 2004;5(1):63-9.

26. Lee $\mathrm{CH}$, Kweon $\mathrm{OK}$. Mutations of $\mathrm{p} 53$ tumor suppressor gene in spontaneous canine mammary tumors. J Vet Sci 2002;3(4):321-5.

27. Lowe SW, Ruley HE, Jacks T, et al. p53-dependent apoptosis modulates the cytotoxicity of anticancer agents. Cell 1993;74(6): 957-67.

28. Finlay CA, Hinds PW, Tan TH, et al. Activating mutations for transformation by $\mathrm{p} 53$ produce a gene product that forms an hsc70-p53 complex with an altered half-life. Mol Cell Biol 1988;8(2): 531-9.

29. Axiotis CA, Monteagudo C, Merino MJ, et al. Immunohistochemical detection of P-glycoprotein in endometrial adenocarcinoma. Am J Pathol 1991;138(4):799-806.

30. Ahnen DJ, Feigl P, Quan G, et al. Ki-ras mutation and p53 overexpression predict the clinical behavior of colorectal cancer: a Southwest Oncology Group study. Cancer Res 1998;58(6):1149-58.

31. Boyce KL, Kitchell BE. Treatment of canine lymphoma with COPLA/LVP. J Am Anim Hosp Assoc 2000;36(5):395-403.

32. Greenlee PG, Filippa DA, Quimby FW, et al. Lymphomas in dogs. A morphologic, immunologic, and clinical study. Cancer 1990; 66(3):480-90.

33. Teske E, van Heerde P, Rutteman GR, et al. Prognostic factors for treatment of malignant lymphoma in dogs. J Am Vet Med Assoc 1994;205(12):1722-8.

34. Valli VE, San Myint M, Barthel A, et al. Classification of canine malignant lymphomas according to the World Health Organization criteria. Vet Pathol 2011;48(1):198-211.

35. Dhaliwal RS, Kitchell BE, Messick J. Canine Lymphosarcoma. Comp Cont Educ Pract Vet 2003;25:572-82.

36. Arao S, Suwa H, Mandai M, et al. Expression of multidrug resistance gene and localization of P-glycoprotein in human primary ovarian cancer. Cancer Res 1994;54(5):1355-9.

37. Pileri SA, Sabattini E, Falini B, et al. Immunohistochemical detection of the multidrug transport protein P170 in human normal tissues and malignant lymphomas. Histopathology 1991; 19(2):131-40.

38. Miller TP, Grogan TM, Dalton WS, et al. P-glycoprotein expression in malignant lymphoma and reversal of clinical drug resistance with chemotherapy plus high-dose verapamil. J Clin Oncol 1991; $9(1): 17-24$.

39. Bell DR, Gerlach JH, Kartner N, et al. Detection of P-glycoprotein in ovarian cancer: a molecular marker associated with multidrug resistance. J Clin Oncol 1985;3(3):311-5.

40. Stewart J, Gorman NT. Multi-drug resistance genes in the management of neoplastic disease. J Vet Intern Med 1991;5(4):239-47.

41. Dalton WS. Alternative (non-P-glycoprotein) mechanisms of drug resistance in non-Hodgkin's lymphoma. Hematol Oncol Clin North Am 1997;11(5):975-86. 
42. Cole SPC, Bhardwaj G, Gerlach JH, et al. Overexpression of a transporter gene in a multidrug-resistant human lung cancer cell line. Science 1992;258(5088):1650-4.

43. Filipits M, Suchomel RW, Zöchbauer S, et al. Multidrug resistanceassociated protein in acute myeloid leukemia: No impact on treatment outcome. Clin Cancer Res 1997;3(8):1419-25.

44. Bosari S, Viale G, Roncalli M, et al. p53 gene mutations, p53 protein accumulation and compartmentalization in colorectal adenocarcinoma. Am J Pathol 1995;147(3):790-8.

45. Baas IO, Mulder JW, Offerhaus GJ, et al. An evaluation of six antibodies for immunohistochemistry of mutant p53 gene product in archival colorectal neoplasms. J Pathol 1994;172(1): 5-12.

46. Greenblatt MS, Bennett WP, Hollstein M, et al. Mutations in the p53 tumor suppressor gene: clues to cancer etiology and molecular pathogenesis. Cancer Res 1994;54(18):4855-78.
47. Pezzella E, Morrison H, Jones M, et al. Immunohistochemical detection of p53 and bcl-2 proteins in non-Hodgkin's lymphoma. Histopathology 1995;22(1):39-44.

48. Said JW, Barrera R, Shintaku IP, et al. Immunohistochemical analysis of p53 expression in malignant lymphomas. Am J Pathol 1992;141(6):1343-8.

49. Wunder JS, Gokgoz N, Parkes R, et al. TP53 mutations and outcome in osteosarcoma: a prospective, multicenter study. J Clin Oncol 2005; 23(7):1483-90.

50. Zhang C, Zhang P, Hao J, et al. High nuclear grade, frequent mitotic activity, cyclin D1 and p53 overexpression are associated with stromal invasion in mammary intracystic papillary carcinoma. Breast J 2005;11(1):2-8.

51. Jones BA, Kasl SV, Howe CL, et al. African-American/White differences in breast carcinoma: p53 alterations and other tumor characteristics. Cancer 2004;101(6):1293-301. 